\title{
Technè
}

La science au service de l'histoire de l'art et de la préservation des biens culturels

$43 \mid 2016$

Une Europe de la recherche en sciences du patrimoine

\section{De Colorando Auro: Medieval colouring techniques researched using modern analytical techniques}

De colorando auro. Les recettes médiévales de coloration de l'or étudiées avec des méthodes d'analyse modernes

Amandine C. Crabbé, Helena J. M. Wouters, Cristian Mocuta, Mathieu Silly, Loïc Bertrand, Herman Terryn and Isabelle Vandendael

\section{(2) OpenEdition}

Journals

Electronic version

URL: http://journals.openedition.org/techne/875

DOI: $10.4000 /$ techne.875

ISSN: 2534-5168

Publisher

C2RMF

\section{Printed version}

Date of publication: 1 August 2016

Number of pages: $120-126$

ISBN: 978-2-7118-6338-9

ISSN: 1254-7867

Electronic reference

Amandine C. Crabbé, Helena J. M. Wouters, Cristian Mocuta, Mathieu Silly, Loïc Bertrand, Herman

Terryn and Isabelle Vandendael, « De Colorando Auro: Medieval colouring techniques researched using modern analytical techniques », Technè [Online], 43 | 2016, Online since 19 December 2019,

connection on 24 July 2020. URL : http://journals.openedition.org/techne/875 ; DOI : https://doi.org/ 10.4000/techne.875

\section{(c) $)(1) \Theta$}

La revue Technè. La science au service de l'histoire de l'art et de la préservation des biens culturels est mise à disposition selon les termes de la Licence Creative Commons Attribution - Pas d'Utilisation Commerciale - Pas de Modification 4.0 International. 

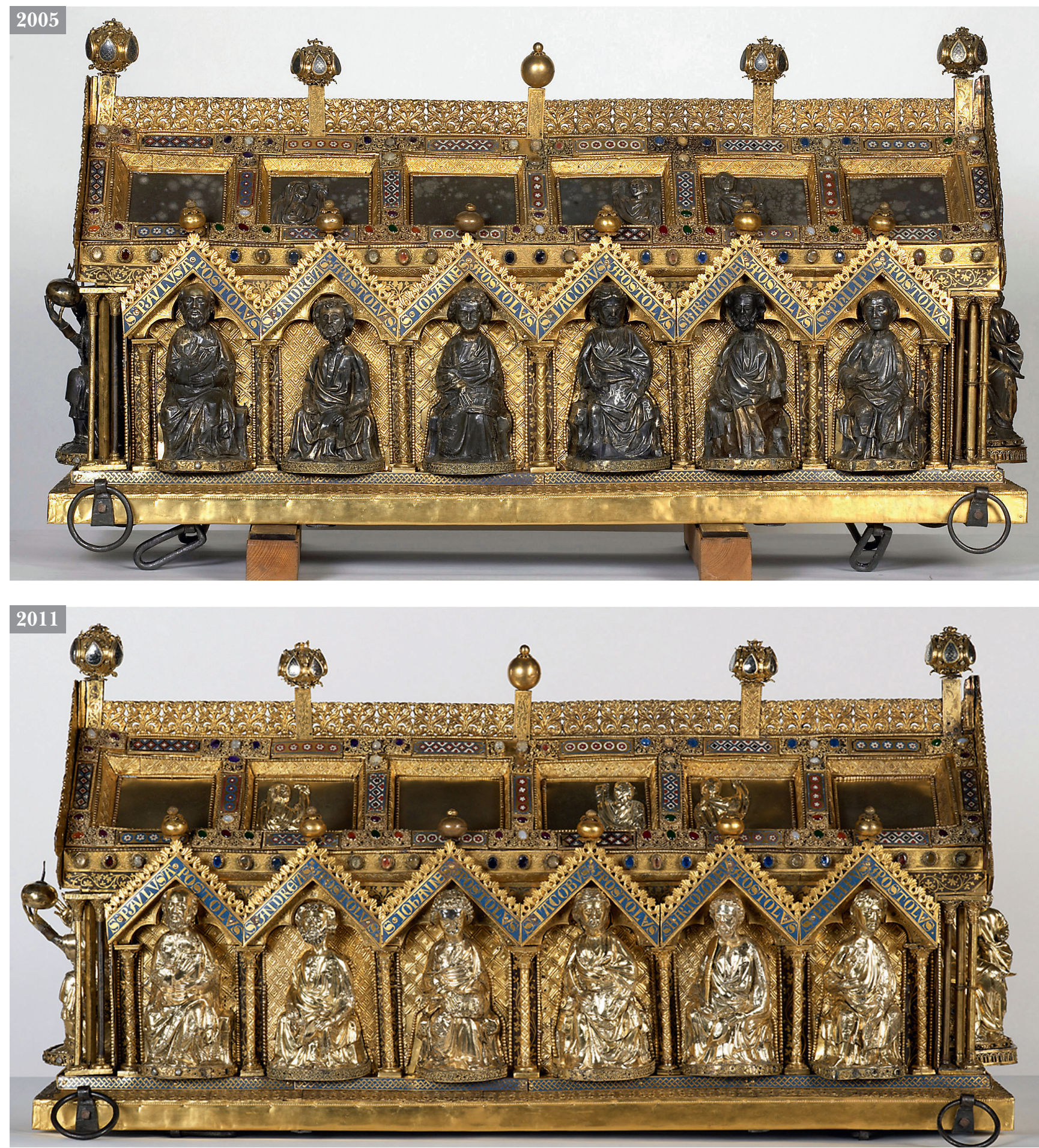

Fig. 1. Pictures of the Holy Lady Shrine of Huy before and after its restoration in 2005 showing the impact of different interpretations of texts of medieval recipes on its final aspect. () KIK-IRPA. 
Amandine C. Crabbé

Helena J. M. Wouters

Cristian Mocuta

Mathieu Silly

Loïc Bertrand

Herman Terryn

Isabelle Vandendael

\section{De Colorando Auro: Medieval colouring techniques researched using modern analytical techniques}

De colorando auro. Les recettes médiévales de coloration de l'or étudiées avec des méthodes d'analyse modernes

Abstract. The visual appearance of gold and gilding can be influenced in many ways, such as by changing the composition of the gold alloy or the nature of the gilded substrate. A less known medieval technique, reported in historical treatises, is the chemical treatment of the gilded surface itself, after application and burnishing of the gilding. We reporte here results regarding the study of the Holy Lady Shrine of Huy (13th c AD Mosan, Belgium) on which a possible artificial colouration of the gildings was detected. This led to many questions regarding applicable conservation-restoration treatments. Here is an overview of the results obtained, along with a discussion of the methodology that was developed to study this colouration process, also highlighting the necessary complementarity between laboratory and synchrotronbased analytical approaches. The 3-steps methodology proposed in this paper is generic for most cultural heritage problems where the application of ancient surface modification recipes is suspected but where the scarcity of the historical samples does not allow a direct study of such samples.

Keywords. Gilding, colouration, XANES, SR-XPS, SEM$E D X$, silver, copper, iron, shrine, cultural heritage.
Résumé. L'aspect visuel de l'or et des dorures peut être modifié de diverses manières, notamment en changeant la composition de l'alliage ou la nature du support doré. Une technique médiévale moins connue, évoquée dans les traités anciens, consiste à provoquer une réaction chimique après application et brunissage de la dorure. Les recherches sur la châsse de Notre-Dame de Huy (art mosan du XIII siècle) ont révélé une possible coloration artificielle des dorures. Cette découverte soulève de nombreuses questions quant aux traitements de conservation-restauration utilisables. Nous présentons ici un exposé sommaire des résultats obtenus ainsi qu'un compte rendu de la méthode mise au point pour étudier ce procédé de coloration, en soulignant la complémentarité indispensable entre les examens de laboratoire et l'analyse par rayonnement synchrotron. Dans les sciences du patrimoine culturel, cette méthode en trois temps concerne la plupart des situations où une recette ancienne semble avoir été employée pour modifier la surface, mais où la rareté des échantillons historiques ne permet pas l'étude directe de sous-échantillons.

Mots-clés. Dorure, coloration, spectroscopie d'absorption des rayons $X$ au voisinage du seuil (XANES), spectroscopie de photoélectrons X par rayonnement synchrotron (SR-XPS), microscopie à balayage électronique-analyse de rayons $X$ par dispersion (SEM-EDX), argent, cuivre, fer, châsse, patrimoine culturel.

\section{Introduction}

The Holy Lady Shrine of Huy (Rheno-Mosan art, 13th century $\mathrm{AD})$ is one of the four major shrines of the Collegiate ${ }^{1}$. It consists of gilded silver and copper plates, enamels, filigranes, and "vernis brun". Despite two previous restoration campaigns, one in the 18th century and the other in 1969, the return of the shrine to the metal conservation studio of the Royal Institute for Cultural Heritage (KIK-IRPA, Brussels) was necessary and took place from 2005 till 2011. During the restoration in 1969, the blackening of the gilded silver statuettes was attributed to the application of "pseudo-nielle"1 which is supposed to give the same appearance as with niello but with a different chemical composition. This hypothesis was based on the detection of iron in the black coating and an interpretation of Theophilus' recipe "Colorando auro"2,3. As a consequence, all the gaps on the statuettes were filled with black micro-crystalline wax and the dark colouration was re-homogenised during the restoration in 1969.

When the shrine returned to the KIK-IRPA in 2005 (see fig. 1 upper part), the assumption made in 1969 of intentionally blackened gilded silver by applying "pseudo-nielle" was reconsidered and called into question for three main reasons. Firstly, there was no evidence of the use of "pseudo-nielle" on

Amandine C. Crabbé, SURF, Vrije Universiteit Brussel (VUB), Brussels (amandine.crabbe@gmail.com). Helena J. M. Wouters, KIK-IRPA, Brussels. Cristian Mocuta, Synchrotron SOLEIL. Mathieu Silly, Synchrotron SOLEIL. Loïc Bertrand, IPANEMA, CNRS, MCC, UVSQ, Université Paris-Saclay, Synchrotron SOLEIL. Herman Terryn, SURF, Vrije Universiteit Brussel (VUB), Brussels. Isabelle Vandendael, SURF, Vrije Universiteit Brussel (VUB), Brussels. 
any other shrine of the same period. Secondly, from a historical and economical point of view, it was hard to imagine that artists would have spent so much effort and money to gild silver statuettes and blacken them afterwards while there were many well-known techniques that could lead to intense black patinas on silver or copper ${ }^{4,5}$. Thirdly, the difficulty to remove the black material from the gilding as argument for application of "pseudo-nielle" can be contested, since it is known that $\mathrm{Ag}_{2} \mathrm{~S}$ (naturally formed corrosion product that results in silver blackening) bonds more strongly on gold than on silver ${ }^{6}$. Different interpretations highly impact the final aspect of the shrine as shown in fig. 1. The upper picture shows the result of the restoration in 1970, based on the "pseudo-nielle" hypothesis, while the lower picture shows the final aspect after the restoration in 2011, after disapproval of that same hypothesis.

The broader question that arose in this context was how to restore and conserve gilded silver art-pieces without damaging them or losing any original material holding information on their history and the technique used to manufacture them.

In order to understand the medieval surface treatments, characterise the results and find traces on historical pieces without damaging them, we developed a full research project using a set of complementary analytical laboratory techniques that included colorimetry, scanning electron microscopy with energy dispersive X-ray spectrometry (SEM-EDX) or X-ray fluorescence (XRF) depending on the size of the samples, and synchrotron radiation (SR) techniques such as the one illustrated in this article: X-ray absorption spectroscopy (XAS) ${ }^{7,8,9}$. In the case of the statuettes from the shrine, X-ray absorption near edge spectroscopy (XANES) not only yielded good results but also proved to be a non-destructive and noninvasive technique ${ }^{10}$. Provided here is an overview of the methodology developed to face this multidisciplinary challenge. We highlight the complementarities between laboratory and SR-based analytical techniques, and the importance of their accessibility for cultural heritage research. Our final aim is to establish the possible use of colouring practices on the gilded silver statuettes of the Shrine.

\section{A 3-step methodology}

To tackle this challenge, we developed a methodology consisting of three major steps: 1) preparation of model samples using medieval gold colouration recipes, 2) characterisation of the model samples and their stability through time, and 3) comparison of the model samples with historical samples.

\section{Preparation of model samples from medieval gold colouration recipes}

A detailed study of the existing medieval gold colouration recipes was performed. To be able to carry out the different possible interpretations of the ancient texts, model samples were needed.
In order to implement medieval recipes in well-controlled situations and robustly interpret their outcomes, the model samples must fulfil two criteria:

- they need to be representative of the real medieval samples originating from the Mosan goldsmith art samples ${ }^{11}$, both in composition and thickness.

- they should be reliable and well-defined ${ }^{12,13}$ in order to distinguish the parameters leading to colour changes from those inducing other alterations.

Recent studies and measurements performed on the statuettes of the Holy Lady Shrine showed that the thickness of ancient fire gildings is between 3 and $30 \mu \mathrm{m}^{11}$. Both 2D and $3 \mathrm{D}$ model samples were developed. Most of the research was done on the 2D model samples shaped by lamination. 3D samples, shaped by the 'repoussé' technique ${ }^{11}$, are closer to the historical samples with respect to metallography. This second type of model sample is needed to link the model samples with historical reality. In both cases, we selected a substrate of $999 \%$ o pure silver (copper traces), covered by fire gilding (24 carat, $20 \mu \mathrm{m}$ thick). The surface of the gilding is burnished with agate stone. Since this research is, to our best knowledge, the first one on chemically modified gilded surfaces using medieval recipes, the model samples are very simple. The fire gilding applied by a professional presents the characteristic structure but contains less than 1000 ppm of mercury at its surface. In a following part of this research, the influence of different amounts of mercury on the recipes should be studied as well as the impact of the impurities present in the reagents. This implies an extensive study for each of the impurities along with mercury.

The temperature applied on fire gildings can modify their colour ${ }^{14}$. Our treatment was therefore applied only on two thirds of the surface of each model sample to allow comparison between the treated and an untreated surface that undergoes the same temperature variations (the Blank).

Recipes used to change the colour of a fire gilded metal surface after it was burnished are found in most of the main silversmith technical treatises prior to the Renaissance period. We focused on historical writings dated between the 3rd and the 15th century such as Leyden and Stockholm Papyrus ${ }^{15-17}$ or the Mappae Clavicula ${ }^{18-22}$. The recipes studied in this research describe (i) the preparation and (ii) the application of a mixture. The main difference between the recipes is the composition of the mixture ${ }^{11}$. We showed that one could modify the surface colour of 24-carat gilding on a silver substrate by applying deciphered medieval recipes ${ }^{2}$. Colorimetric analyses quantified colour shifts to the red (red/green scale) and to the yellow (yellow/blue scale) $)^{13,23}$. The analytical results of two recipes are presented to illustrate the methodology discussed in this paper. Interpretation of the first recipe $(\mathrm{RMC} 100)^{13}$ resulted in four possible mixtures; two with a $\mathrm{pH}$ around 2 and two with a $\mathrm{pH}$ around 9. The difference between the two resulting $\mathrm{pH}$ values is due to two possible interpretations of the word "salt" in the recipe. Researched literature, history and chemical indication present in other parts of the document in the Mappae Clavicula writing, 
Table 1. Overview of possible mixtures for the two recipes considered for this study, with their respective measured $\mathrm{pH}$.

\begin{tabular}{|c|c|c|c|c|c|c|c|c|c|}
\hline 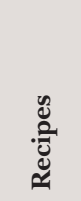 & 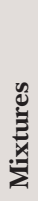 & $\begin{array}{l}0^{+} \\
\text {bे } \\
\text { I }\end{array}$ & $\begin{array}{l}\bar{U} \\
\bar{Z}\end{array}$ & $\begin{array}{l}\bar{J} \\
\vec{Z} \\
\vec{Z}\end{array}$ & $\begin{array}{l}\mathcal{O}^{\infty} \\
\text { Z̃ } \\
\text { Zै }\end{array}$ & $0^{\infty}$ & 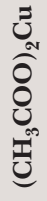 & $0^{\infty}$ & $\frac{\pi}{2}$ \\
\hline \multirow{4}{*}{$\begin{array}{c}\text { RMC } \\
100\end{array}$} & $\mathbf{a}$ & $\bullet$ & & & $\bullet$ & $\bullet$ & $\bullet$ & & $\bullet$ \\
\hline & $\mathbf{b}$ & $\bullet$ & & & $\bullet$ & $\bullet$ & & & 9.5 \\
\hline & c & • & $\bullet$ & & & • & $\bullet$ & & 2 \\
\hline & d & $\bullet$ & $\bullet$ & & & • & & & 1.5 \\
\hline RC V & & & & • & & & • & $\bullet$ & 3.5 \\
\hline
\end{tabular}

suggests it can be either $\mathrm{NaCl}$ or $\mathrm{Na}_{2} \mathrm{CO}_{3}$. A second difference may arise from the description concerning the pot used to prepare the mixture. It can be made of copper as well as ceramic. In the case of a copper pot, copper acetate would be present in the mixture even though it is not part of the ingredients. The other reagents are $\mathrm{FeSO}_{4}$ and $\mathrm{Fe}_{2} \mathrm{O}_{3}$. The second recipe used in this article is identified as $\mathrm{RC} \mathrm{V}^{13}$. It is important to mention its use as it contains no iron compounds in its reagents. The five mixtures' reagents are presented in table 1.

The results of the tests show that when a change in colour occurs, acidic mixtures cause the gilding to appear redder. Alkaline mixtures modify the surface aspect but the colour change is not detected by visual examination ${ }^{13}$. The results can be observed in fig. 2 for the RMC 100 mixtures.

\section{Physical and chemical characterisation of the treated model samples: the complementarity of laboratory and SR measurements}

The physical and chemical modifications of the treated gilding surfaces were studied and their stability monitored through time.

\section{Physical characterisation of the freshly coloured model samples}

Depending on the acidic or basic properties of the mixture applied to the surface of the gilding, different surface modifications are observed. With acidic mixtures the colours shift more towards red, yellow and light colours in the CIELAB colour space ${ }^{24}$ as shown by the blue and pink arrows in fig. 3 (3D representation in three frames: $\mathrm{XY}$ view $=$ green $/$ red on yellow/blue scales; $\mathrm{XZ}$ view = green $/$ red on light $/$ dark scales and $\mathrm{YZ}$ view = yellow/blue on light/dark scales). The colour obtained is homogeneous on a macroscopic scale, but inhomogeneous on a microscopic one. On this scale, the surface appears to be composed of red, orange, yellow and even grey areas. It shows that, using implemented medieval recipes, it is possible to modify the colour of a fire gilding after it has been applied and burnished. High magnification pictures acquired with the FEG-SEM show that the surface undergoes an inhomogeneous chemical etching. With alkaline mixtures the colour shifts towards a more blue-green colour in the CIELAB space (see red and green arrows on fig. 3). On a microscopic scale, the treated gilding stays mostly yellow like the Blank but its surface is less even. High magnification images also show chemical etching of the surface but clearly less than with acidic mixtures. The results are diverse for the different mixtures and the full set of samples and recipes shows that the impact of the etching increases with decreasing $\mathrm{pH}$.

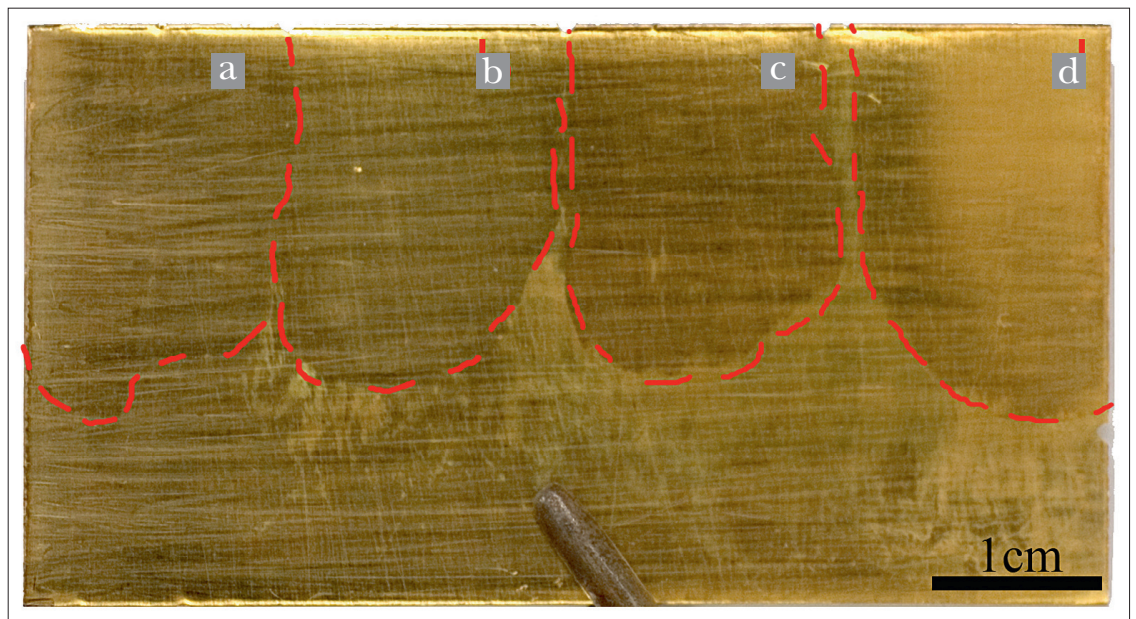

Fig. 2. Picture of the visible effects of applying the four possible mixtures of RMC 100 on a model sample.
Chemical characterisation of the freshly coloured model samples

Based on chemical characterisation with XRF and SEM-EDX (fig 4), the recipes tested in the study can be classified into three groups. In group I, iron is the chemical signature of the applied colouring treatment (RMC 100c, RMC 100d). Copper is identified as the chemical signature in group II (e.g. RC V). The copper chemical signature is not an obvious result. Although copper compounds are present in the reagents of all applied recipes, as well as an impurity in the gilding, the copper concentration only increases significantly at the surface of the coloured samples when no iron is present in the mixture. This is the case for all recipes of group II. Finally, the two alkaline mixtures do not modify the chemical 


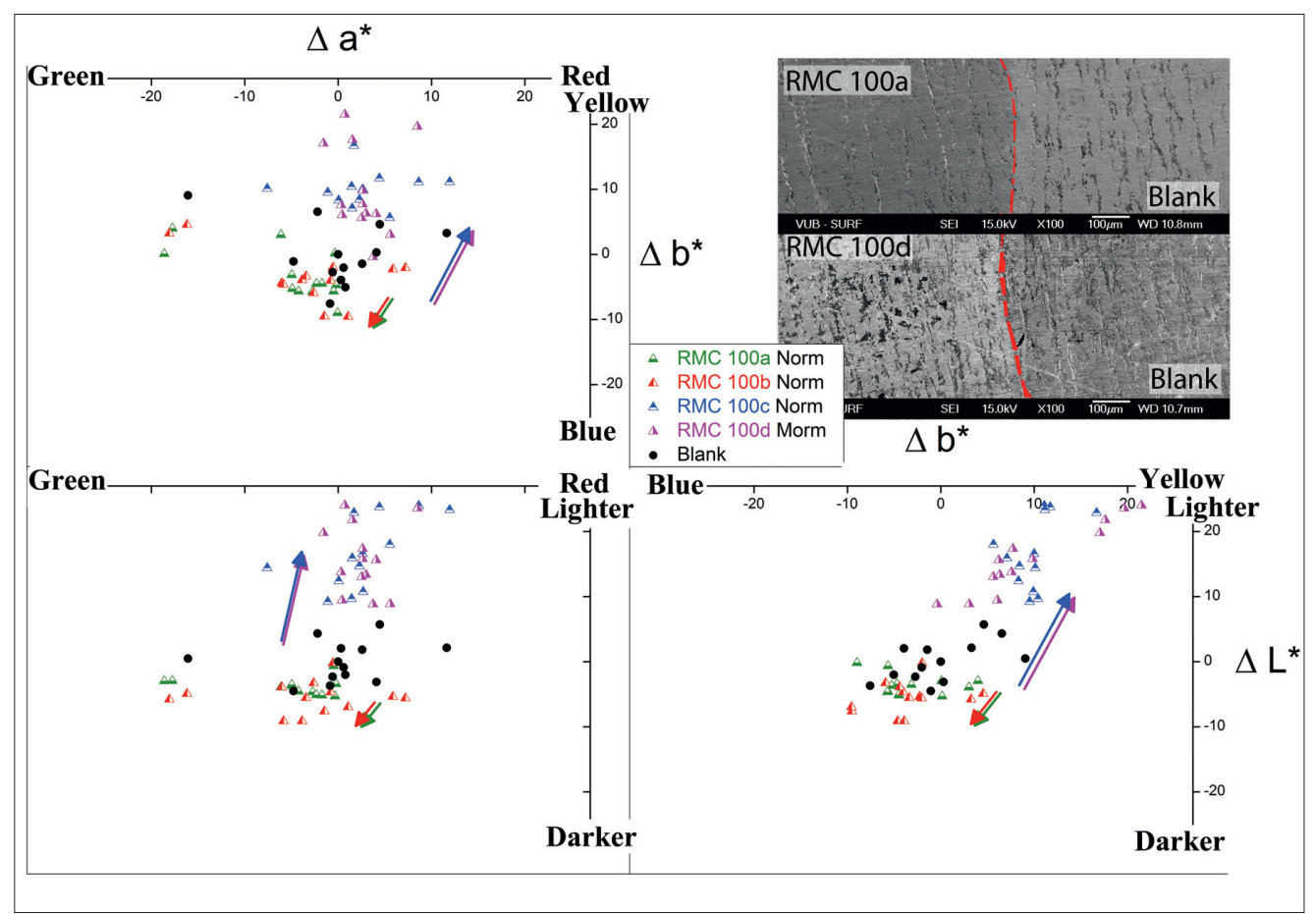

Fig. 3. Shifts in the CIELAB space for the four different RMC 100 mixtures and two examples of FEG-SEM pictures of surface topography modifications observed after alkaline (RMC 100a) and acid (RMC 100d) mixture treatment.

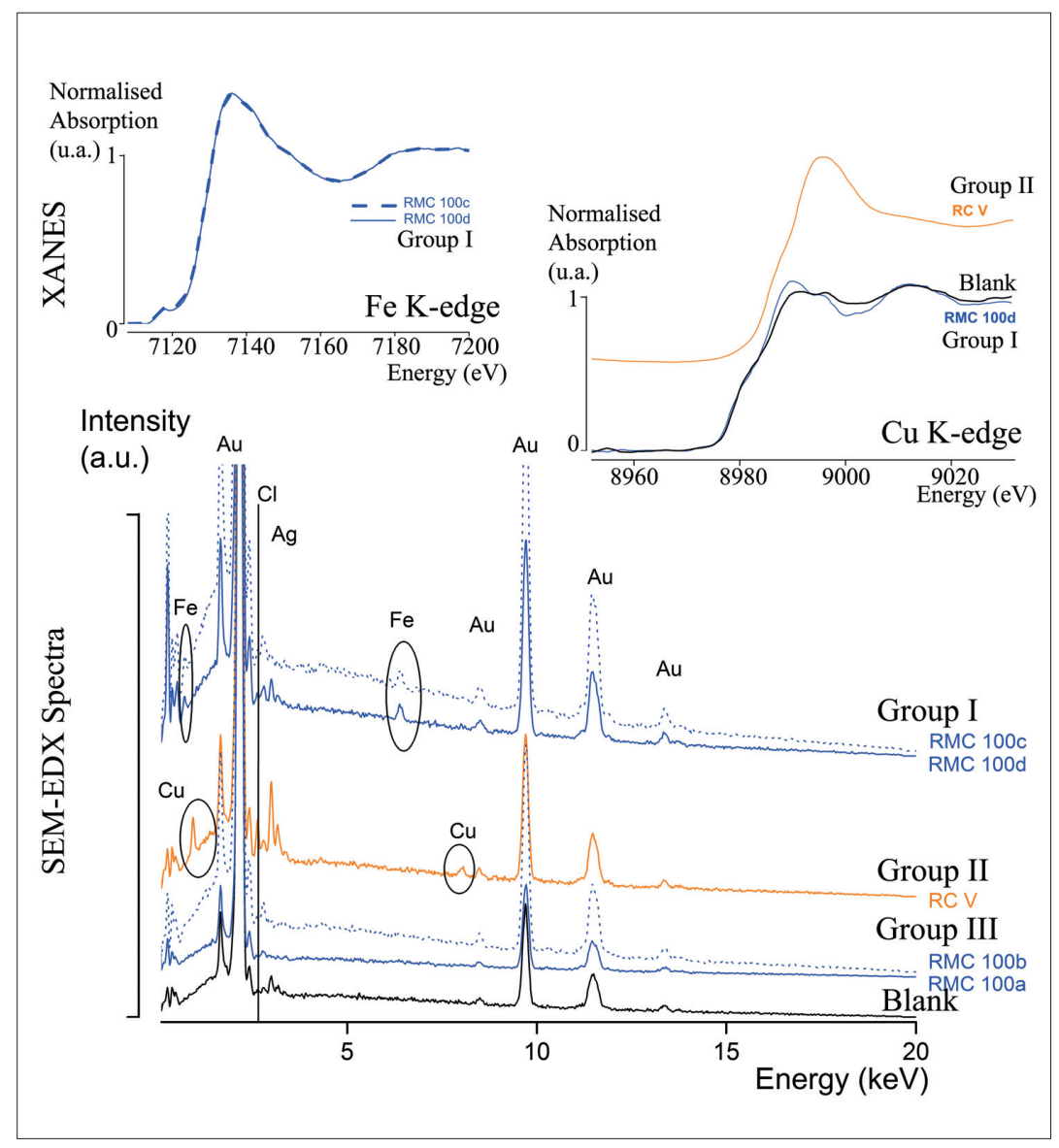

Fig. 4. SEM-EDX and XANES spectra of the treated model samples. The SEM-EDX spectra illustrate the 3 groups of recipes tested. The XANES spectra are used to characterise the iron and copper chemical compounds present at the surface. composition of the surface, giving rise to group III (RMC 100a, RMC 100b).

The iron signature is characterised using synchrotron-based XANES at synchroton SOLEIL (fig. 4). On the XANES spectra, iron at the surface of the model samples from group I appears mainly in the second oxide state (evaluated on the position of the first inflection point in energy). XANES at the copper K-edge clearly shows differences between the samples from groups I and II (fig. 4). For the copper detected on model samples treated with the recipes of group I, we observed a first inflection point of the copper edge positioned $1 \mathrm{eV}$ lower in energy than for $\mathrm{Cu}^{0}$. It is similar to the one observed for the copper measured on the blank. Further investigations are needed at this point to elucidate this position. Some elements of explanation, such as the matrix effect on the copper K-edge measured in gold alloys, can be found in Kuhn et al. studies $^{25}$.

The results presented in fig. 3 and fig. 4 show that modifications in both the chemistry and the morphology of the surfaces can be associated with colour change. For instance, while the RMC 100a and RMC 100b treatments, leading to a shift to a more bluegreen colour, do not modify the surface chemical composition, the colour shift is 
attributed to chemical etching that damages and thins down the gilding. Etching increases non-specular light scattering by the metallic surface and allows the silver substrate to contribute more to the colour of the gilding. Similar surface modifications are observed on the gildings treated with the other recipes, where the colour of the gildings of these samples shifts more to red, yellow and light colours. The most probable explanation is that modification of the chemical composition of the gilding surface is a significant factor in determining the final colour.

\section{Stability of the surface through time after} colouration

To bring the model samples closer to the historical samples ${ }^{26,27}$, they were artificially aged using four potentially aggressive factors; UV light $\left(\mathrm{AA}_{\mathrm{UV}}\right)$, relative humidity and temperature cycles $\left(\mathrm{AA}_{\mathrm{T} / \mathrm{RH}}\right)$, chlorine $\left(\mathrm{AA}_{\mathrm{Cl}}\right)$ and sulphur $\left(\mathrm{AA}_{\mathrm{S}}\right)$ pollutants ${ }^{28}$. Existing testing methods (ASTM testing B117) and set-ups (ATLAS Suntest CPS+) were used to mimic the effects of $\mathrm{AA}_{\mathrm{Cl}}$ and $\mathrm{AA}_{\mathrm{UV}}$. The $\mathrm{AA}_{\mathrm{T} / \mathrm{RH}}$ method ${ }^{27}$ mimics indoor atmospheric conditions found in churches ${ }^{10}$. To study the effects of $\mathrm{AA}_{\mathrm{S}}$, a new type of testing was developed for this research project.

Only $\mathrm{AA}_{\mathrm{S}}$ and $\mathrm{AA}_{\mathrm{Cl}}$ led to significant alteration of the model samples surfaces ${ }^{27}$. Their impact on the surface morphology is so important that no further morphological distinction could be made between the coloured and Blank areas on a microscopic scale. When exposed to $\mathrm{AA}_{\mathrm{S}}$ or $\mathrm{AA}_{\mathrm{Cl}}$, the coloured areas of the samples degraded significantly faster than on the Blank, indicating that the colouring treatment induces a weakening of the protective properties of the gilding. XANES measurements showed that both iron and copper signatures are modified,suggesting that they are not stable through time and react during $\mathrm{AA}_{\mathrm{S}}$ and $\mathrm{AA}_{\mathrm{Cl}}{ }^{10}$.

\section{Comparison with historical samples}

The comparison between the historical samples and the artificially aged model samples allows obtaining information about the surface treatments originally applied to the silver gilded statuettes of the Holy Lady Shrine of Huy.

These historical samples are very precious and chemical analyses are limited and strongly regulated. Within this study, we could analyse several tiny fragments from two statuettes ${ }^{10,27}$. Our SEM-EDX surveys show that iron is associated to the presence of gold (gilding) (fig. 5). The iron identified by XANES may not directly originate from surface deposits from cleaning powders: spectra recorded at the iron K-edge on the statuettes' samples and on a cleaning powder reference material (Rouge à polir', fig. 5) differ significantly.
XANES at the Fe K-edge and all the other surface analyses and testing (fig. 5) indicate that it is highly possible that the historical samples were surface colour treated. Although the recipes used cannot be identified yet, spectra at the Cu K-edge measured on the historical samples and on the Blank (fig. 6) clearly differ for the two statuettes under investigation, which may be attributed to two distinct recipes being used.

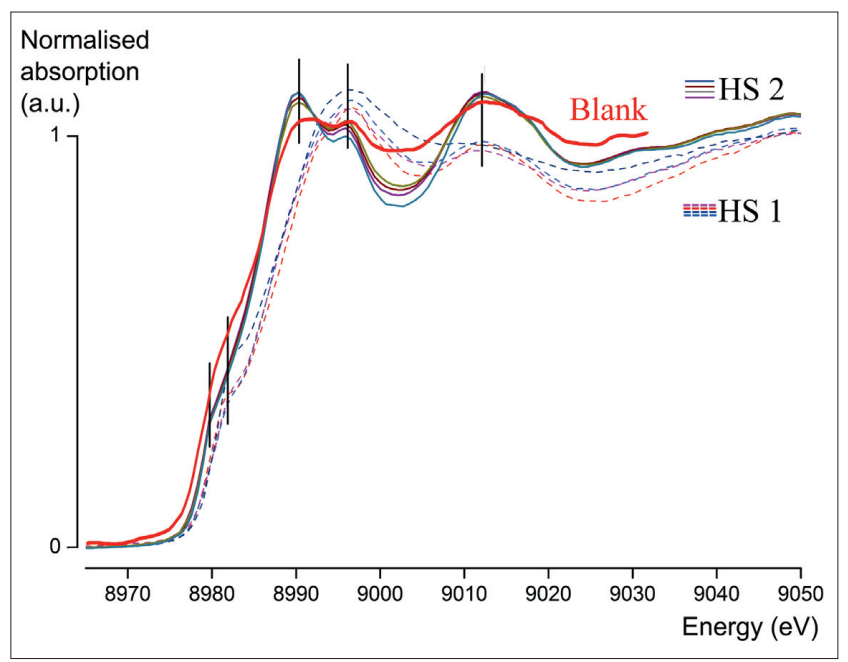

Fig. 6. XANES spectra recorded at the Cu K-edges show significant differences (particularly at energies indicated by the vertical lines) between the historical samples from the two statuettes (HS 1 and HS 2), indicating that both statuettes might have been colour treated with different recipes.

Fig. 5. Multiple EDX spectra recorded on one of the historical samples presence of gold and iron. The comparison of XANES spectra at the Fe K-edge from 'Rouge à polir' and the historical samples (full line: HS 1 and dash line: HS 2) shows that the detected iron most probably does not originate from surface deposit from such a cleaning product. 


\section{Conclusions and perspectives}

The overall methodology developed during this research and illustrated in this paper proved to be adequate to solve the questions regarding the eventual colouration of the Holy Lady Shrine of Huy. It is generic for most cultural heritage problems where the application of ancient surface treatments is suspected but where the scarcity of the historical samples does not permit a direct study of such samples. More specifically, the synchrotron based analytical techniques proved to be complementary to the classical laboratory techniques and allowed non-invasive and non-destructive measurement of the historical pieces.

The most significant outcomes for the shrine are summarised as follows. The colour of 24-carat fire gilding can be modified after application of a colouration recipe and burnishing. The colour alteration is due to physical modifications (the gilding is etched and thinned) and in some cases also due to chemical variations (signatures of iron or copper in different oxidation states). These chemical signatures (Fe and $\mathrm{Cu}$ compounds) are not stable through time. Etched by the colour treatment, the gilding is weakened. It could explain the peculiar aspect of the $\mathrm{Ag}_{2} \mathrm{~S}$, as observed during the restoration in 1969. All our observations converge towards past application of colouring treatments on the gilded silver statuettes of the shrine. At least two different colouration traces are present on the surface of the statuettes today, which may result from two different recipes.

In this study, the medieval recipes were implemented using pure chemical compounds on fire gilding containing a very low concentration of mercury at the surface. As a continuation of this study, it might be worthwhile to also include the possible effects of impurities on the colouration as well as the impact of different concentrations of mercury in the gilding. Spectra at the Cu K-edge could be studied in more detail to understand the chemistry of copper in the gilding and to better identify the recipes possibly used. XRF measurements recorded on gilded silver decorations from other medieval shrines showed the presence of Fe traces. Measuring XANES spectra at the iron K-edge on these traces would allow comparing them with our results. The complementary use of such analyses will contribute to a deeper understanding of the importance of this colouring practice on medieval shrines.

\section{Acknowledgements}

We acknowledge SOLEIL synchrotron facility for supplying beamtime for the XANES studies reported here. We gratefully acknowledge M.-A. Languille (IPANEMA CNRS), S. Reguer, D. Thiaudière (DiffAbs beamline, SOLEIL), and G. Dewanckel (Metals conservation studio, KIK-IRPA) for support, collaboration and constructive suggestions. The research leading to these results has received funding from the Belgian Science Policy (SPP) and the Transnational Access to Research Infrastructures activity in the 7th Framework Programme of the EU (CHARISMA Grant Agreement n. 228330). The IPANEMA platform is jointly developed by CNRS, MNHN, the French Ministry of Culture and Communication and SOLEIL, and benefits from a CPER grant (MENESR, Région Île-de-France).

\section{Bibliography}

1. Didier R. et al., 1970, Bulletin de l'IRPA, XII, 5-85.

2. Crabbé A. C. et al., 2008, Journal of Interface and Surface Analysis, 40, 469-473.

3. Hawthorne J. G. et al., 1963, Theophilus on Divers Arts - The foremost Medieval Treatise on Painting, Glassmaking and Metalwork, Mineola: Dover Pub.

4. Mathis F. et al., 2009, Journal of Cultural Heritage, 10 (11), 63-72.

5. Craddock P. et al., 2013, Metal Plating

and Patination: Cultural, technical and historical developments, 101.

6. Egan T. F. et al., 1960, J. Electrochem. Soc., 107 (14), 353-354.

7. Bertrand L. et al., 2015, Top. Curr. Chem. In press.

8. Bertrand L. et al., 2012, Appl. Phys. A, 106(2), 377-396

9. Bertrand L. et al., Journal of Cultural Heritage (2013) 14(4), 277-289.

10. Crabbé A. C. et al., 2015, JAAS 30, 677-684
11. Wouters H. J. M., 2009, Materials and Manufacturing processes 24 (19) 1033-1040. 12. Crabbé A. C. et al., 2013, Appl Phys. A, 111 (11), 39-46.

13. Crabbé A. C. et al., 2015, Studies in conservation,

10.1179/2047058415Y.0000000013.

14. Anheuser K., 1997, JOM 58-62.

15. Berthelot M. et al., 1906, Archéologie et histoire des sciences, Imprimeur-libraire des comptes rendus des séances de l'Académie des Sciences.

16. Halleux R., 1990, in Pigments et colorants de l'Antiquité et du Moyen Âge teinture, peinture, enluminure, étude historique et physico-chimique, 173-180.

17. Radcliffe E., 1926, in J. Chem. Educ. 3, 1149 .

18. Phillips T., 1847, Mappae Clavicula, Soc. Of Antiquaries of London.

19. Halleux R., 1981, Les alchimistes grecs, I Papyrus de Leyden Papyrus de Stockholm, Les Belles Lettres.

20. Smith C., Hawthorne J., 1974, Mappae Clavicula: a little key to the world of medieval techniques, American Philosophical Society.

21. Berthelot M. et al., 1967, Histoire des Sciences et de la Chimie au Moyen Âge, Paris: Zeller.

22. Crabbé A. C. et al., 2011, Archives des Bibliothèques de Belgique, 94, 1581-1591.

23. Crabbé A. C. et al., 2013, Surface Engineering, 29 (12), 159-163.

24. Tilley R. J. D., 2010, Colour and the optical properties of Material: An Exploration of the Relationship between light, the optical properties of material and colour, London, Wiley.

25. Kuhn M. et al., 1994, Phys. Rev. B 49, 1647-1661.

26. Aucouturier M. et al., 2004, Technè, $n^{\circ} 19,115-122$.

27. Crabbé A. C. et al., 2013, ICOM-CC Metal meeting Proceedings, 247-251.

28. Bouquet S. et al., 1993, Comptes rendus de l'Académie des Sciences, 316 (14), 459-464. 